\title{
异质性光对野牛草叶片解剖结构的影响
}

\author{
郝晨淞王庆凯 孙小玲* \\ 天津农学院园艺园林学院, 天津 300384
}

\begin{abstract}
摘 要 自然界中植物生长所需资源通常呈异质性分布, 具有发达匍甸茎的野牛草(Buchloe dactyloides)在蔓延过程中相连克 隆分株常生活在异质性的光环境中。有研究证明, 在异质性光条件下, 植株幼叶的叶片解剖结构受成熟叶所处光照条件的影响, 而异质性光条件下克隆分株的叶片形态解剖结构是否也受相连分株所处光照条件的影响则未见报道。通过设置高光(全光照)和 低光(遮阴)两个水平, 对由匍匐茎相连的野牛草克隆分株施以同质和异质性光处理, 研究了异质性光对野牛草叶片解剖结构的 影响。结果发现: 在异质性光环境中, 遮阴的野牛草克隆分株的主脉直径、维管束鞘细胞个数、叶片厚度以及近轴侧和远轴侧 叶肉细胞的厚度均显著降低; 同质性的低光处理对这些指标则没有显著影响。在异质性光处理下, 未遮阴姊株近轴侧和远轴侧 叶肉细胞的厚度以及远轴侧的气孔大小显著增加, 而未遮阴的妹株近轴侧和远轴侧叶肉细胞的厚度、气孔密度和气孔大小、叶 片厚度和维管束鞘细胞个数则会降低。同质高光处理下克隆分株近轴侧和远轴侧的气孔密度和气孔大小显著高于同质低光。野 牛草克隆分株近轴侧和远轴侧叶肉细胞的厚度、气孔密度和气孔大小受相连分株所处光照条件的显著影响。该研究结果表明: 未遮阴的姊株因为与遮阴的妹株相连而显著受益, 而未遮阴的妹株则因为与遮阴的姊株相连而损耗严重; 在异质性光处理 下, 遮阴分株叶片形态上缩减的可塑性生长是为减少维持其存活的消耗，提高遮阴分株存活率的一种适应性表现。
\end{abstract}

关键词 野牛草; 异质性光; 解剖结构; 气孔密度

引用格式: 郝晨㳂, 王庆凯, 孙小玲 (2016). 异质性光对野牛草叶片解剖结构的影响. 植物生态学报, 40, 246-254. doi: 10.17521/cjpe.2015.0377

\section{Effects of light heterogeneity on leaf anatomical structure in Buchloe dactyloides}

\author{
HAO Chen-Song, WANG Qing-Kai, and SUN Xiao-Ling* \\ College of Horticulture and Landscape Architecture, Tianjin Agricultural University, Tianjin 300384, China
}

\begin{abstract}
Aims Essential resources for plant growth are usually patchily distributed. During the process of propagation, interconnected ramet pairs of stoloniferous plant buffalograss (Buchloe dactyloides) may therefore experience contrasting resource supply such as light. Under heterogeneous light supply, anatomical structure of newly developed leaves is regulated by the light condition of mature leaves. However, little is known about whether leaf anatomical structure of clonal ramets is affected by the light environment of interconnected ramets in clonal plants under heterogeneous light supply.
\end{abstract}

Methods Two light levels were set, with high light (natural sunlight) and low light (shade, 10\% natural sunlight). Interconnected ramet pairs of buffalograss were exposed to homogeneous or heterogeneous light conditions.

Important findings Main vein diameter, bundle sheath cell number, leaf thickness and adaxial/abaxial mesophyll thickness of shaded ramets were remarkably decreased in spatially heterogeneous light environment; while no signifiacnt difference of these parameters was observed between ramets developed under homogeneous high light and low light conditions. Under heterogeneous light supply, adaxial/abaxial mesophyll thickness and abaxial stomatal size in unshaded elder daughter ramets (EDR) were remarkably increased, while adaxial/abaxial mesophyll thickness, stomatal density and size, leaf thickness, and bundle sheath cell number in unshaded younger daughter ramets (YDR) were reduced. Ramets under homogeneous high light conditions had higher stomatal density and larger stomata than those under homogeneous low light conditions. Adaxial/abaxial mesophyll thickness, stomatal density and size in buffalograss ramets were significantly affected by the light conditions of interconnected ramets.

Conclusions Unshaded EDR benefit from their connection to shaded YDR, while unshaded YDR experience marked cost due to its connection to shaded EDR. The plastic decrease of shaded ramets under heterogeneous

收稿日期Received: 2015-10-20 接受日期Accepted: 2016-02-19

* 通信作者Author for correspondence (E-mail: xiaolingsun@tjau.edu.cn) 
light may be associated with its reduced survival cost, and elevated survival rate under shading.

Key words buffalograss; light heterogeneity; anatomical structure; stomatal density

Citation: Hao CS, Wang QK, Sun XL (2016). Effects of light heterogeneity on leaf anatomical structure in Buchloe dactyloides. Chinese Journal of Plant Ecology, 40, 246-254. doi: 10.17521/cjpe.2015.0377

异质性环境条件是普遍存在的, 异质性光条件 是具有发达匍匐茎的植物在曼延过程中不可避免的 环境限制因素。当克隆植物相互连接的克隆分株处 于资源水平不同的小生境时, 相连分株之间可能会 存在养分、水分或光合产物的克隆整合, 这种克隆 整合通常被认为是植物适应自然条件的一种表现 (Yu et al., 2004)。目前对异质性光条件下克隆整合 的研究, 绝大多数局限于对生物量(Stuefer et al., 1994; Alpert, 1999; Guo et al., 2011)、克隆形态 (Magyar et al., 2007)的研究, 还有少数对光合参数 (Wang et al., 2008; Li et al., 2011; 陶应时等, 2013) 和激素含量(Alpert et al., 2002; Qian et al., 2010)的 研究, 在异质性光条件下克隆植物叶片解剖结构的 差异尚缺乏相关研究。

光是植物生长的重要因素, 在遮阴胁迫下, 植 物叶片在解剖结构上会发生一系列变化, 如叶片变 大变薄、栅栏组织和海绵组织的厚度变小、栅栏组 织细胞排列较疏松、细胞密度减小、叶片中叶绿体 数目变少、叶绿体基粒垛叠较少、细胞间隙增大、 气孔数目变少等(Murchie \& Horton, 1997; Weijschedé et al., 2006; 韦海建等, 2007; Jiang et al., 2011)。来源于北美大草原的 $\mathrm{C}_{4}$ 植物野牛草(Buchloe dactyloides) 是京津地区重要的护坡植物。 $\mathrm{C}_{4}$ 植物叶 片的显著特征是维管束周围具有发达的维管束鞘细 胞形成的花环结构, 维管束鞘细胞中含有较大的叶 绿体, 其与周围放射状排列的叶肉细胞间存在大量 的胞间连丝, 有利于光合产物的运转。在 $\mathrm{C}_{4}$ 植物中, 大气中的 $\mathrm{CO}_{2}$ 首先在叶肉细胞中被初步固定生成 $\mathrm{C}_{4}$ 酸, 随后 $\mathrm{C}_{4}$ 酸被转移到维管束鞘的薄壁细胞中, 释 放 $\mathrm{CO}_{2}$, 参与卡尔文循环, 形成碳水化合物, 因此维 管束鞘细胞与叶肉细胞的接触面积直接影响着代谢 产物 $\mathrm{C}_{4}$ 酸的运输速率, 接触面积越高, 代谢产物传 递的效率越高, 越能保证 $\mathrm{C}_{4}$ 植物光合作用的有效进 行(Jiang et al., 2011)。近轴侧和远轴侧叶肉细胞的厚 度决定着叶肉细胞面向外围空间的表面积, 叶肉细 胞厚度越厚, 叶肉细胞面向外围的空间越大, 为叶 绿体的排布提供了广阔空间, 越有利于 $\mathrm{CO}_{2}$ 进入叶
绿体并被固定(巩玥等, 2014)。

Karpinski等(1999)发现将适应低光处理的拟南 芥(Arabidopsis thaliana) 部分重新置于高光处理下 时, 没有经过高光处理的拟南芥叶片也会作出一个 系统调整，表现出对过多激发能和光氧化的响应。 此后, 其他科学家陆续发现拟南芥、烟草(Nicotiana tabaccum)和高粱(Sorghum bicolor)新生叶的叶片厚 度、近轴侧和远轴侧叶肉细胞厚度、近轴侧和远轴 侧的气孔密度、维管束鞘细胞表面积和栅栏组织的 解剖学特征均取决于成熟叶所处的光照条件, 而非 自身所处的光照条件(Lake et al., 2001; Thomas et al., 2004; Jiang et al., 2011)。换言之, 对于同一株植 物来说, 由于遮阴的成熟叶与不遮阴的新生叶之间 存在着信号联系, 致使未遮阴的新生叶表现出阴生 植物的特点, 因此新生叶的叶片形态解剖结构受自 身光照条件的影响不大。

野牛草被认为是一种“游击型”植物(Qian et al., 2010), 它会区分环境质量, 选择资源丰富的生境, 而避开资源匮乏的生境。野牛草的克隆分株基本会 被匍匐茎终生联系在一起，在蔓延过程中，由匍匐 茎相连的姊妹分株时常处于不同的光照条件。我们 想知道在异质性光条件下由匍匐茎相连的年龄不同 的野牛草克隆分株之间是否也会存在胁迫信号的传 导, 而这与其能够有效地侦测环境质量的“游击型” 特性是否有关? 在本实验中, 我们将同一母株繁殖 出的由匍匐茎相连的姊妹分株作为一个处理单位, 切断其与母株的关联后, 施以同质和异质性光处理, 通过测定不同光处理下野牛草叶片的解剖结构和气 孔指标的差异, 来分析异质性光处理是如何影响野 牛草克隆分株的叶片解剖结构特征的, 以及由匍匐 茎相连的年龄不同的姊妹分株之间是否也会存在胁 迫信号的传导。

\section{1 材料和方法}

\section{1 材料种植和试验设计}

本试验采用盆栽实验方法, 用·斯巴克’ 野牛草 作为试验材料，种子由北京绿冠集团提供。2014年5 
月1日播种，2014年7月15日选出长势良好且整齐的 野牛草作为母株, 包括 $1.5 \mathrm{~cm}$ 长主匍匐茎, 3 个叶片、 $3 \mathrm{~cm}$ 长须根被栽培在栽培槽 $(42 \mathrm{~cm} \times 17.5 \mathrm{~cm} \times 13.5$ $\mathrm{cm})$ 中, 使用草炭:蛭石 $(\mathrm{V}: \mathrm{V})=1: 1$ 作为基质。试验期 间, 母株的匍匐茎被安置在一条线上, 离母株最近 的两个相连分株依次扎根, 离母株近的分株称之为 姊株(elder daughter ramet, EDR), 离母株远的分株 称之为妹株(younger daughter ramet, YDR)。试验期 间不让其他分株扎根。在分株之间使用塑料硬纸板 隔开, 以防止克隆分株的根系相互缠结, 并能起到 防止匍匐茎埋入土中腐烂的作用。塑料板被安置在 栽培槽的中间位置, 保证姊妹株所在斑块大小的一 致性。2014年8月22号，待姊妹分株均扎根后，保留 由匍匐茎相连的姊妹分株, 剪除其他部分(图1)。恢 复生长一周后, 对野牛草克隆分株实施同质性光 (同质高光HH、同质低光 $\mathrm{LL}$ ) 和异质性光(姊株高光 妹株低光HL、姊株低光妹株高光LH)处理(表1)。高 光为正常光照; 低光用 $90 \%$ 遮阴效果的遮阳网进行 遮阴处理(10\%正常光照)。每个处理7个重复, 在试 验期间保证匍匐茎的完整性。试验共持续4个月。

所有试验处理的分株对被随机放置于温室内, 定期移位以减少位置因素造成的误差。异质性光处 理之前, 保证所有分株形态和大小的一致性, 留3个 叶片, 根系剪至 $3 \mathrm{~cm}$ 长。实验过程中, 每个栽培槽每 周浇30 mL的全能Hoagland营养液(4.373 $\mathrm{g} \mathrm{NH}_{4} \mathrm{NO}_{3}$. $\mathrm{L}^{-1}, 2.063 \mathrm{~g} \mathrm{NaH}_{2} \mathrm{PO}_{4} \cdot \mathrm{L}^{-1}$ 和 $\left.2.876 \mathrm{~g} \mathrm{KCl} \cdot \mathrm{L}^{-1}\right)$, 两个分 株各浇 $15 \mathrm{~mL}$, 保证植物对养分的基本需求 $(\mathrm{Yu} \&$ Dong, 2003)。定期浇水, 保证植物不受到水分胁迫。

\section{2 叶片解剖结构的观察和测量}

对于不同光处理的野牛草克隆分株, 选取刚刚 成熟的叶片, 在靠近主脉基部的 $1 / 3$ 处取材 $(3 \mathrm{~mm} \times$ $3 \mathrm{~mm}$ ), 立即用FAA固定液(福尔马林:乙酸: $50 \%$ 乙 醇体积比为 10:3:87)固定, 用LEICA ASP200S脱水 机(Leica, Wetzlar, Germany)乙醇脱水, 中性树脂封 片, 番红-固绿双重染色法染色, LEICA RM2235切 片机(Leica, Wetzlar, Germany)切片, 切片厚度为7-8 $\mu \mathrm{m}$ 。然后在LEICA DM4000B LED光学显微镜 (Leica, Wetzlar, Germany)下观察, 用LEICA DFC450 照相机(Leica, Wetzlar, Germany)进行显微照相, 用 LAS AF Lite图像分析软件测量主脉直径、维管束鞘 细胞与叶肉接触面的长度, 维管束鞘细胞个数、叶

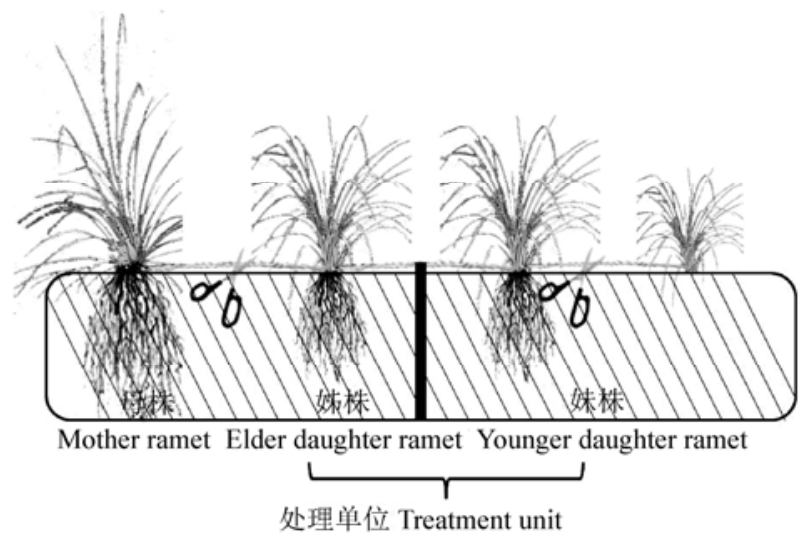

图1 试验开始时由匍匐茎连接的野牛草母株、姊株和妹株。 Fig. 1 Diagrammatic presentation of a Buchloe dactyloides stolon segment consisting of mother ramet, elder daughter ramet and younger daughter ramet at the start of this experiment.

表1 姊妹分株接受的不同光处理

Table 1 The pattern of light treatments to elder daughter ramets (EDR) and younger daughter ramets (YDR)

\begin{tabular}{lll}
\hline 试验处理 Treatment & 姊株 EDR & 妹株 YDR \\
\hline $\mathrm{HH}$ & 高光 High light & 高光 High light \\
$\mathrm{HL}$ & 高光 High light & 低光 Low light \\
$\mathrm{LH}$ & 低光 Low light & 高光 High light \\
$\mathrm{LL}$ & 低光 Low light & 低光 Low light \\
\hline
\end{tabular}

片厚度、近轴侧和远轴侧叶肉细胞厚度等指标。近 轴侧和远轴侧叶肉细胞厚度的测定参照Jiang 等 (2011)的方法, 选取维管束中央(叶片中间)的位置 拉线, 以区别近轴侧和远轴侧叶肉细胞。叶肉细胞 厚度以维管束中央点为中心, 测定径向排列的叶肉 细胞的宽度。每个处理7次重复。

\section{3 气孔密度的测定}

采用印迹法测定气孔密度。选取各处理下刚刚 成熟的植物叶片, 将透明指甲油涂抹在叶片的上下 表皮, 待指甲油干透后, 用透明胶带取下指甲油薄 片, 置于载玻片上, 然后在LEICA DM4000B LED 光学显微镜下, 用LEICA DFC450照相机进行显微 照相, 在LAS AF Lite图像分析软件中清点气孔数 目、测定保卫细胞的长度。由于气孔的张开程度随 时在变, 因此选用保卫细胞的长度代表气孔的最大 张开程度, 即气孔的大小, 而没有测定气孔的实际 张开程度(Xu \& Zhou, 2008)。选取7株样本, 每个样 本中随机选取 6 个视野。 


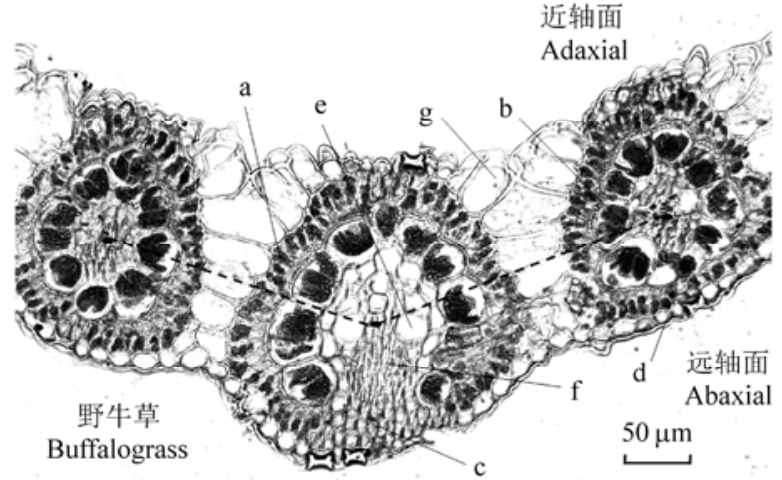

图2 光学显微镜下野牛草叶片的横切结构图。近轴侧和远 轴侧叶肉细胞厚度的测定参考Jiang等(2011)的方法, 选取维 管束中央(叶片中间)的位置拉线, 如上图的虚线所示。 $a$, 叶 肉细胞; b, 维管束鞘细胞; c, 厚壁组织; $d$, 表皮细胞; e, 木 质部; f, 韧皮部; $\mathrm{g}$, 泡状细胞。

Fig. 2 Illustration of an image used to measure the adaxial (lower) and abaxial (upper) mesophyll tissues of Buchloe dactyloides in a cross-section light micrograph. The adaxial and abaxial mesophyll thickness were measured separately relative to the middle of the bundle sheath as shown by the dashed line, which generally represented the middle of the leaf (Jiang et al., 2011). a, mesophyll cells; b, bundle sheath cells; c, sclerenchyma; d, epidermal cell; e, xylem; f, phloem; g, motor cell.

\section{4 数据处理}

使用SPSS 20.0软件进行数据分析。用三因素方 差分析(three-way ANOVA)比较年龄、分株自身所处光 照条件与相邻分株所处光照条件对各指标的影响以及 它们之间的交互作用。用单因素方差分析(one-way ANOVA)比较同一指标不同处理之间的差异显著性, 并用Duncan法对均值进行多重比较, $p=0.05$ 。

\section{2 结果和分析}

\section{1 主脉维管束特征}

三因素方差分析的结果表明主脉直径、维管束
鞘细胞个数、维管束鞘细胞与叶肉接触面的长度受 分株自身所处光照条件和相连分株所处光照条件 交互作用的显著影响(表2)。同质性的低光处理对 相连分株的主脉直径、维管束鞘细胞个数、维管束 鞘细胞与叶肉接触面的长度没有显著影响(图3)。

在异质性光处理下，遮阴分株的维管束鞘细胞个 数显著降低(图3B); 遮阴的姊妹株的主脉直径(图 $3 \mathrm{~A})$ 、遮阴妹株的维管束鞘细胞与叶肉接触面的长 度(图3C)与同质高光相比也显著降低。在异质性光 环境中, 未遮阴妹株的维管束鞘细胞个数显著降 低; 而未遮阴姊株的维管束鞘细胞个数则没有显著 变化(图3B)。

\section{2 叶片厚度与叶肉细胞厚度}

三因素方差分析的结果表明, 野牛草克隆分株 近轴侧和远轴侧叶肉细胞的厚度受年龄和相连分株 所处光照条件的显著影响(表2)。同质高光处理下， 野牛草妹株近轴侧和远轴侧的叶肉细胞厚度分别比 姊株厚约 $47.6 \%$ 和 $47.3 \%$ (图4B, 4C)。同质性的低光 对姊株的叶片厚度没有显著影响，却显著增加了姊 株近轴侧(42.5\%)和远轴侧叶肉细胞的厚度 $(53.1 \%)$ (图4)。在异质性光处理下, 遮阴姊株的叶片厚度、 近轴侧和远轴侧叶肉细胞的厚度, 以及遮阴妹株远 轴侧叶肉细胞的厚度均显著降低(图4); 未遮阴姊株 近轴侧和远轴侧叶肉细胞的厚度显著增加, 而未遮 阴妹株近轴侧和远轴侧叶肉细胞的厚度, 以及叶片 厚度则显著降低(图4)。与异质光环境中其他叶片解 剖指标的变化不同, 遮阴妹株近轴侧的叶肉细胞厚 度甚至大于未遮阴的妹株(图4B)。

表2 年龄、分株自身所处光照条件和相连分株所处光照条件及其交互作用对野牛草叶片解剖特征的三因素方差分析

Table $2 \quad F$-values of three-way ANOVA for the effects of age (A), local condition ( $\mathrm{Lc}$ ), remote condition (Rc), and their interactions on leaf anatomical traits of Buchloe dactyloides

\begin{tabular}{|c|c|c|c|c|c|c|c|c|c|c|c|}
\hline $\begin{array}{l}\text { 处理 } \\
\text { Treatment }\end{array}$ & $\begin{array}{c}\text { 自由度 } \\
\text { Degree } \\
\text { of } \\
\text { freedom } \\
\end{array}$ & $\begin{array}{c}\text { 主脉直径 } \\
\text { MVD }\end{array}$ & $\begin{array}{c}\text { 维管束鞘细 } \\
\text { 胞个数 } \\
\text { BSCN }\end{array}$ & $\begin{array}{c}\text { 维管束鞘细胞 } \\
\text { 与叶肉接触面 } \\
\text { 的长度 } \\
\text { CLBM } \\
\end{array}$ & $\begin{array}{c}\text { 叶片 } \\
\text { 厚度 } \\
\text { LT }\end{array}$ & $\begin{array}{c}\text { 近轴侧叶肉 } \\
\text { 细胞厚度 } \\
\text { AdMT }\end{array}$ & $\begin{array}{c}\text { 远轴侧叶肉 } \\
\text { 细胞厚度 } \\
\text { AbMT }\end{array}$ & $\begin{array}{c}\text { 近轴侧 } \\
\text { 气孔密度 } \\
\text { AdSD }\end{array}$ & $\begin{array}{c}\text { 远轴侧 } \\
\text { 气孔密度 } \\
\text { AbSD }\end{array}$ & $\begin{array}{c}\text { 近轴侧 } \\
\text { 气孔大小 } \\
\text { AdSZ }\end{array}$ & $\begin{array}{c}\text { 远轴侧 } \\
\text { 气孔大小 } \\
\text { AbSZ }\end{array}$ \\
\hline 年龄 A & 1,48 & 0.754 & 0.388 & 0.017 & 1.168 & $4.19^{*}$ & $4.28^{*}$ & 0.368 & 0.116 & $33.925^{* * *}$ & $22.998^{* * *}$ \\
\hline $\begin{array}{l}\text { 分株自身所处光照 } \\
\mathrm{Lc}\end{array}$ & 1,48 & $10.667^{* *}$ & 0.028 & 1.864 & 4.027 & 0.910 & 3.740 & $23.540^{* * *}$ & $31.030^{* * *}$ & $55.845^{* * *}$ & $85.684^{* * *}$ \\
\hline $\begin{array}{l}\text { 相连分株所处光照 } \\
\text { Rc }\end{array}$ & 1,48 & 3.265 & 0.447 & 0.209 & 0.559 & $8.380^{* *}$ & $17.550^{* * *}$ & $29.793^{* * *}$ & $35.030^{* * *}$ & $130.628^{* * *}$ & $98.520^{* * *}$ \\
\hline $\mathrm{A} \times \mathrm{Lc}$ & 1,48 & 0.018 & 2.495 & 0.988 & 0.008 & 0.110 & 1.630 & 0.828 & 0.485 & $37.874^{* * *}$ & $102.998^{* * *}$ \\
\hline $\mathrm{Lc} \times \mathrm{Rc}$ & 1,48 & $11.227^{* *}$ & $28.096^{* * *}$ & $6.339^{*}$ & $10.221^{* *}$ & $16.570^{* * *}$ & $20.700^{* * *}$ & $4.506^{*}$ & 1.486 & 2.041 & 0.112 \\
\hline $\mathrm{A} \times \mathrm{Rc}$ & 1,48 & 0.883 & $4.457^{*}$ & 0.001 & 1.380 & $12.780^{* * *}$ & 3.730 & 0.092 & 0.059 & $21.304^{* * *}$ & $81.604^{* * *}$ \\
\hline $\mathrm{A} \times \mathrm{Lc} \times \mathrm{Rc}$ & 1,48 & 0.285 & 2.592 & 1.299 & 0.079 & 1.390 & 3.490 & 0.368 & 0.021 & 0.592 & $66.281^{* * *}$ \\
\hline
\end{tabular}

MVD, main vein diameter; BSCN, bundle sheath cell number; CLBM, total contact length between bundle sheath and mesophyll cells; LT, Leaf thickness; AdMT, adaxial mesophyll thickness; AbMT, abaxial mesophyll thickness; AdSD, adaxial stomatal density; AbSD, abaxial stomatal density; AdSZ, adaxial stomatal size; AbSZ, abaxial stomatal size. *, $p<0.05 ;{ }^{* *}, p<0.01 ; * * *, p<0.001$; ns, $p>0.05$. 

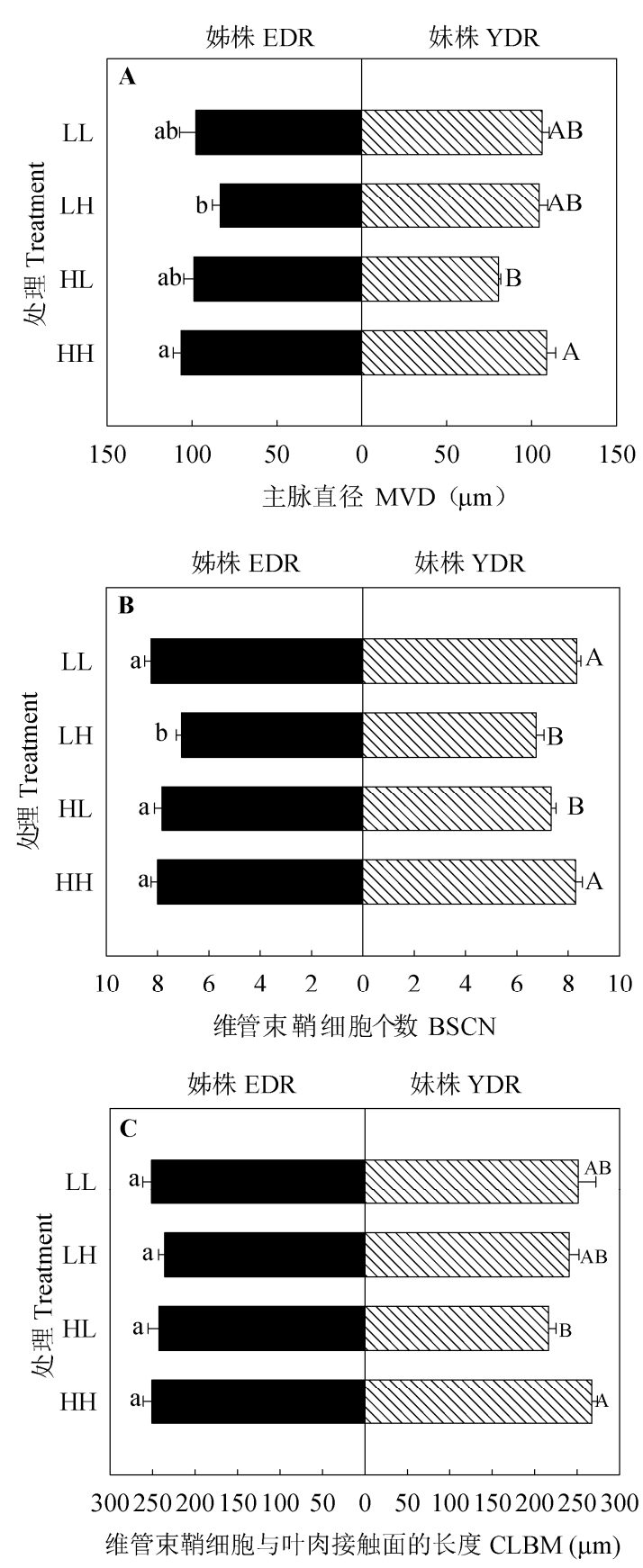

图3 同质和异质性光处理下野牛草姊株和妹株的主脉直径 (A)、维管束鞘细胞个数 (B) 和维管束鞘细胞与叶肉接触面的 长度 $(\mathbf{C})$ (平均值 \pm 标准误差, $n=7$ )。不同小写/大写字母表示 处理间差异显著 $(p<0.05)$ 。HH、HL、LH、LL同表1。

Fig. 3 Main vein diameter (MVD) (A), bundle sheath cell number $(\mathrm{BSCN})(\mathbf{B})$, and total contact length between bundle sheath and mesophyll cells (CLBM) (C) of Buchloe dactyloides elder daughter ramets (EDR) and younger daughter ramets (YDR) under homogeneous and heterogeneous light treatments (means $\pm S E, n=7$ ). Different letters indicate significant difference among treatments $(p<0.05)$. For HH, HL, LH and LL, see Table 1.

\section{3 气孔密度与气孔大小}

同质高光条件下野牛草克隆分株的气孔密度
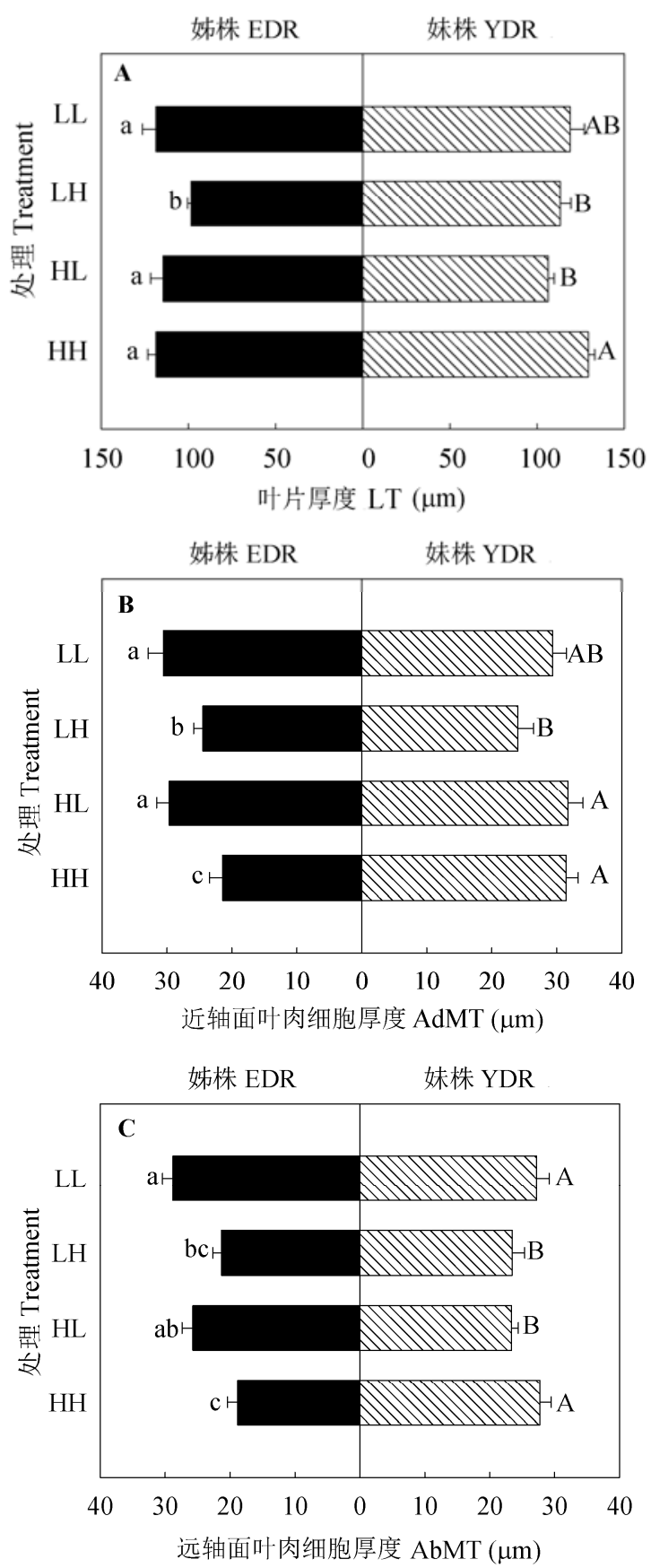

图4 同质和异质性光处理下野牛草姊株和妹株的叶片厚度 (A)、近轴侧叶肉细胞的厚度 $(\mathbf{B})$ 和远轴侧叶肉细胞的厚度 $(\mathbf{C})$ (平均值 \pm 标准误差, $n=7$ )。不同小写/大写字母表示处理间差 异显著 $(p<0.05)$ 。HH、HL、LH、LL同表1。

Fig 4 Leaf thickness (LT) (A), adaxial mesophyll thickness (AdMT) (B), and abaxial mesophyll thickness (AbMT) (C) of Buchloe dactyloides elder daughter ramets (EDR) and younger daughter ramets (YDR) under homogeneous and heterogeneous light treatments (means $\pm S E, n=7$ ). Different letters indicate significant difference among treatments $(p<0.05)$. For $\mathrm{HH}$, HL, LH and LL, see Table 1.

和大小显著高于同质低光条件下的相应分株(图5)。 在不同的光处理下，野牛草姊株的气孔密度和大小 
的变化与妹株存在一致性(图5)。三因素方差分析的 结果证明, 姊妹株近轴侧和远轴侧的气孔密度和大 小不仅受自身所处光照条件的显著影响, 还受相连 分株所处光照条件的显著影响(表2)。分株对的气孔 密度和大小在异质性光处理下基本的变化趋势是: 未遮阴分株的气孔密度和大小均降低, 遮阴分株的 气孔密度和大小增大(图5)。比较特殊的是在异质性 光处理下, 未遮阴的姊株远轴面的气孔显著增大。 综合在异质性光处理下未遮阴妹株远轴面的气孔显 著变小(图5D), 未遮阴的姊妹株远轴面气孔这一响 应与同条件下姊妹株近轴面和远轴面叶肉细胞厚度 的变化是一致的(图4B, 4C), 即在异质性光条件下, 野牛草分株远轴面气孔形态的变化与近轴和远轴面 叶肉细胞的厚度变化存在一致性。综合在异质性光 处理下, 遮阴的姊妹株远轴面的气孔密度与同质高
光相比显著降低, 而近轴面的气孔密度与同质高光 相比则没有显著变化，说明野牛草分株远轴面的气 孔密度和大小对光的反应比近轴面要敏感。

\section{3 讨论}

\section{1 异质光环境下, 野牛草克隆分株的解剖学适应}

植物的表型可塑性是指植物可以通过形态、生 理和发育特性的改变来适应环境的变化。同质性的 遮阴生境下, 野牛草克隆分株叶片的解剖结构与同 质性高光处理差异不大(除气孔密度与大小外), 这 种现象在刺楸(Kalopanax pictus)和䔉(Chenopodium album)中也有报道(Oguchi et al., 2003, 2008)。在遮 阴生境中, 刺楸叶肉细胞中存在大量没有被叶绿体 填充的空隙, 林窗形成以后, 叶肉细胞内表面的叶 绿体覆盖面积增加了 $17 \%$, 而光合效率增加了 $27 \%$,
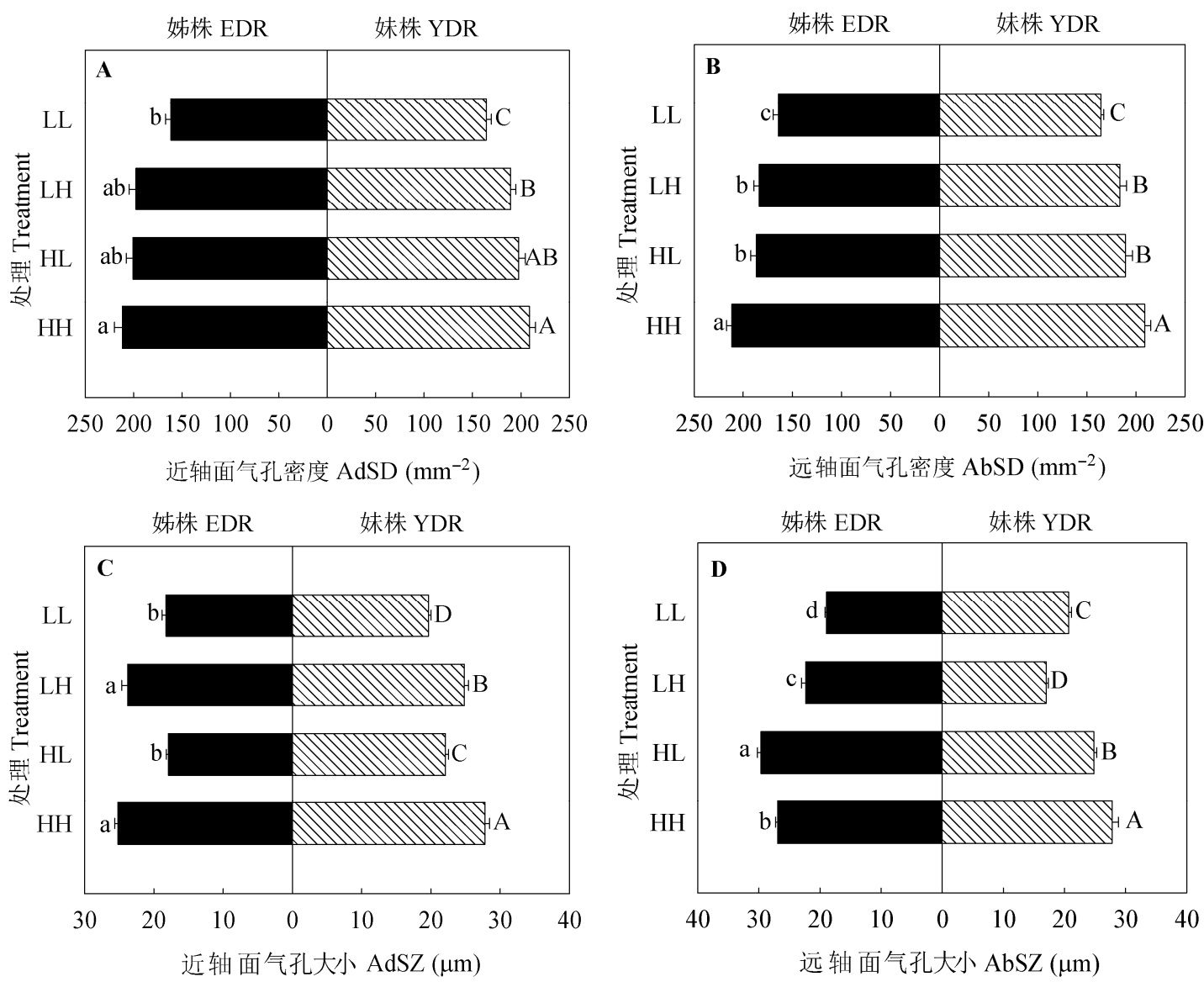

图5 同质和异质性光处理下野牛草姊株和妹株近轴侧和远轴侧的气孔密度(A和B)以及近轴侧和远轴侧的气孔大小 (C和D) (平均值土标准误差, $n=7)$ 。不同小写/大写字母表示处理间差异显著 $(p<0.05)$ 。HH、HL、LH、LL同表1。

Fig. 5 Adaxial stomatal density (AdSD) (A), abaxial stomatal density (AbSD) (B), adaxial stomatal size (AdSZ) (C) and abaxial stomatal size (AbSZ) (D) of Buchloe dactyloides elder daughter ramets (EDR) and younger daughter ramets (YDR) under homogeneous and heterogeneous light treatments (means $\pm S E, n=7)$. Different letters indicate significant difference among treatments $(p<$ 0.05). For HH, HL, LH and LL, see Table 1. 
说明叶绿体变化对光合作用的影响可能要大于叶片 厚度变化(Oguchi et al., 2008)。植物的形态可塑性仅 在通过形态改变能获取更多资源的情况下才是有益 的，而且形态可塑性同时是伴随一定损耗的，例如 维护的损耗、信号识别和传输的损耗等, 无论这种 形态可塑性是增长还是缩减 (Alpert \& Simms, 2002), 可能这些导致在同质重度遮阴条件下, 野牛 草克隆分株叶片解剖形态与同质高光相比并无显著 差异。当然, 野牛草也可能直接通过减少叶肉细胞 内叶绿体个数的方式来适应低光, 尚需通过电镜测 定叶绿体微结构等方式进一步证实。

在异质性光处理下, 野牛草遮阴分株的主脉直 径、维管束鞘细胞个数、叶片厚度、近轴侧和远轴 侧叶肉细胞的厚度均显著降低; 而同质性的低光对 这些指标则没有显著影响。Weijschedé等(2006)也曾 报道三叶草(Trifolium repens)的叶柄长度在异质性 光条件下可塑性要优于同质性遮阴的条件。有些形 态可塑性是被动的, 例如在遮阴生境中, 叶片由于 光照资源不足导致的叶片长度变短(van Kleunen \& Fischer, 2007)。而在本实验中, 异质性光处理下, 遮 阴分株叶片形态结构的可塑性改变应该是一种主动 的形态可塑性, 而且是有益的。在 4 个月的遮阴实验 过程中, 同质性的遮阴生境下野牛草的死亡率很高 $(60 \%)$, 而异质性的遮阴条件下却没有野牛草克隆 分株死亡的现象。因此这种形态上缩减的可塑性生 长实际为了减少在异质光环境中维持遮阴分株存活 的消耗, 保证其存活率, 应该是野牛草在异质性生 境下的一种特殊的存活机制。

\section{2 异质光环境中, 高光处理下姊妹株的不同响应}

在异质光处理下, 未遮阴的姊株近轴侧和远轴 侧叶肉细胞的厚度都显著增加, 远轴侧的气孔也变 大了。在异质光环境中野牛草未遮阴姊株表现出性 能显著提高的这种响应与匍匐委陵菜(Potentilla reptans)和蕨麻(Potentilla anserina) 类似, 异质光处 理下未遮阴的匍匐委陵菜和鄀麻分株生物量显著增 加, 作者认为可能与克隆分工有关, 即未遮阴分株 可能受到遮阴分株的水分资助(Stuefer et al., 1994)。 Qian等(2010)使用 ${ }^{14} \mathrm{CO}_{2}$ 示踪法, 发现在野牛草中没 有胁迫时光合产物的传输以向顶传输为主; 在幼株 遭受胁迫时, 向顶传输的光合产物量会显著增加。 在本研究中, 异质性光处理下未遮阴的姊株近轴侧 和远轴侧叶肉细胞厚度显著增加, 我们推测, 因为
野牛草光合产物的传输以向顶传输为主, 根据源和 库的反馈作用机制，对妹株遮阴导致库效应增大， 未遮阴姊株通过增加叶肉细胞的厚度提高光合能 力, 生产更多的光合产物以资助被遮阴的妹株。

在异质光环境中, 未遮阴妹株近轴侧和远轴侧 叶肉细胞的厚度、气孔密度和气孔大小、叶片厚度, 以及维管束鞘细胞个数均显著降低, 未遮阴妹株在 异质性光处理下产生损耗的原因应该与胁迫信号的 传导有关。Jiang等(2011)证明同为 $\mathrm{C}_{4}$ 植物的高粱在 成熟叶遮阴的条件下, 新生叶明显表现出阴生植物 的特点, 如叶片上下表皮气孔密度变小, 叶片厚度 和近轴侧叶肉细胞厚度减小, 维管束鞘细胞与叶肉 的接触面积减少, 碳同化能力和气孔导度下降, 更 易发生光抑制; 而对新生叶遮阴, 对成熟叶的这些 指标则没有显著的影响。根据遮阴的成熟叶会给予 未遮阴的新生叶胁迫信号的理论(Lake et al., 2001; Thomas et al., 2004; Jiang et al., 2011), 我们推断遮 阴胁迫下的姊株(老株)应该是对妹株(幼株)发出了 胁迫信号, 导致未遮阴的妹株做出了对遮阴胁迫的 形态响应。

姊妹株叶片解剖形态上的这种变化趋势与我们 观测到的在异质性光处理下, 未遮阴的姊妹株其他 形态(如匍匐茎长度、个数、叶片宽度等)上的变化 以及光合参数的变化是一致的(未发表)。野牛草姊 妹株在异质性光处理下, 未遮阴分株叶片解剖结构 和气孔上这种不同的响应可能与其“游击型”的生长 特性相关, 以避开胁迫生境, 通过老株将更多幼株 安置于资源丰富的生境中。然而这一理论还没有相 关报道, 需要进一步的实验证明。

\section{3 气孔密度和大小受相连克隆分株所处光照条 件的共同影响}

植物对遮阴的一般响应是叶片气孔密度变小 (Abrams \& Kubiske, 1990; Jiang et al., 2011), 本研 究的结果与其基本相符。同质高光条件下, 克隆分 株叶片的气孔密度最高; 其次为异质性光环境中的 高光和低光处理; 同质性的低光条件下, 姊妹株叶 片的气孔密度最低。一般干旱生境中植物的气孔较 小, 也有研究证明阳生植物的气孔大于阴生植物, 但也有研究发现气孔大小在阴生和阳生植物中并无 规律可循(Abrams \& Kubiske, 1990; James \& Bell, 2000)。在本研究中, 同质高光下生长的分株气孔大 于同质低光下生长的相应分株。高光下气孔变大与 
高光下植物需要依赖气孔蒸滕进行叶片降温有关, 而且气孔越多越大, 蒸滕作用越旺盛, 越能有效地 吸收土壤养分(James \& Bell, 2000)。

野牛草克隆分株叶片近轴侧和远轴侧的气孔密 度和大小不仅受分株自身所处光照条件的影响, 还 受相连分株所处光照条件的显著影响。在异质性光 处理下, 遮阴分株的气孔密度和大小增大; 未遮阴 分株的气孔密度和大小减小。根据成熟叶和新生叶 之间信号传导的理论, Lake等(2001)认为新生叶的 气孔密度之所以会受成熟叶所处光照条件的影响, 是因为新叶在展开前不能准确地监测外界的 $\mathrm{CO}_{2}$ 浓 度, 而成熟叶却可以准确地探测大气中 $\mathrm{CO}_{2}$ 的浓度 以控制气孔的开闭和数量。我们推测野牛草克隆分 株的叶片在发育过程中不仅受分株自身成熟叶发出 的信号的影响, 还受相连分株成熟叶给予的信号的 影响。

在异质性光处理下, 遮阴妹株近轴侧的气孔密 度和叶肉细胞厚度与同质高光相比没有显著差异 (图4B, 图5A); 而远轴侧的气孔密度和叶肉细胞厚 度显著低于同质高光处理下的相应分株(图4C, 图 $5 \mathrm{~B})$, 说明相连姊株所处的高光条件对妹株近轴侧 的气孔密度和叶肉细胞厚度的影响高于远轴侧。野 牛草妹株近轴侧和远轴侧叶肉细胞厚度和气孔密度 对光信号的不同响应源于等面叶近轴侧和远轴侧对 光信号的响应是不对称的。Long等(1989)曾证明在 等面叶 $\mathrm{C}_{4}$ 植物中, 叶片的近轴和远轴侧中间存在一 个 $\mathrm{CO}_{2}$ 扩散的物理障碍, $\mathrm{CO}_{2}$ 的扩散和碳同化过程基 本可被视为两个不同的隔断。这种分隔开隔断的叶 片系统不仅可以优化光合作用, 而且可以分开传达 胁迫的信号(Soares-Cordeiro et al., 2009)。譬如在高 粱中, 新生叶近轴侧的气孔密度和叶肉细胞厚度对 成熟叶传输的胁迫信号更敏感(Jiang et al., 2011)。在 本实验中, 野牛草幼株近轴侧的叶肉细胞厚度和气 孔密度对相连老株传输的高光信号比远轴侧敏感。 在异质性光处理下, 野牛草未遮阴分株远轴侧的气 孔大小与近轴和远轴侧叶肉细胞厚度的变化保持高 度的一致性(图4B、4C, 图5D)。同为单子叶 $\mathrm{C}_{4}$ 植物 的玉米(Zea mays)和高粱叶片远轴侧的光合和呼吸 速率总是高于近轴侧(Driscoll et al., 2006; 王晓琳 等, 2012), 因为单子叶 $\mathrm{C}_{4}$ 植物一般原产于光照比较 充足的低纬度地区, 强光容易使近轴侧叶肉细胞发 生光抑制, 导致光合速率下降, 而远轴侧的叶片一
般不会因为光照或 $\mathrm{CO}_{2}$ 浓度改变而发生光抑制, 从 而可以一直有效地进行光合作用(王晓琳等, 2012)。 因此野牛草远轴侧气孔形态的这种调控有助于提高 整个野牛草克隆分株的光合效率。

\section{基金项目 国家自然科学基金 (31201847)。}

致谢 感谢天津农学院科技发展基金 (2012D04) 和 天津市大学生创新创业训练计划项目 (市级) (2014-10061010) 资助。

\section{参考文献}

Abrams MD, Kubiske ME (1990). Leaf structural characteristics of 31 hardwood and conifer tree species in central Wisconsin: Influence of light regime and shade-tolerance rank. Forest Ecology and Management, 31, 245-253.

Alpert P (1999). Clonal integration in Fragaria chiloensis differs between populations: Ramets from grassland are selfish. Oecologia, 120, 69-76.

Alpert P, Holzapfel C, Benson JM (2002). Hormonal modification of resource sharing in the clonal plant Fragaria chiloensis. Functional Ecology, 16, 191-197.

Alpert P, Simms EL (2002). The relative advantages of plasticity and fixity in different environments: When is it good for a plant to adjust? Evolutionary Ecology, 16, 285-297.

Driscoll SP, Prins A, Olmos E, Kunert KJ, Foyer CH (2006). Specification of adaxial and abaxial stomata, epidermal structure and photosynthesis to $\mathrm{CO}_{2}$ enrichment in maize leaves. Journal of Experimental Botany, 57, 381-390.

Gong Y, Chen HM, Jiang CD, Shi L (2014). Quantification of leaf anatomical structure and its application in a $\mathrm{C}_{4}$ plant, sorghum. Chinese Bulletin of Botany, 49, 173-182. (in Chinese with English abstract) [巩玥, 陈海苗, 姜闯道, 石雷 (2014). 植物叶片解剖结构的量化及其在 $\mathrm{C}_{4}$ 植物 高粱中的应用. 植物学报, 49, 173-182.]

Guo W, Song YB, Yu FH (2011). Heterogeneous light supply affects growth and biomass allocation of the understory fern Diplopterygium glaucum at high patch contrast. PLoS ONE, 6, e27998.

Karpinski S, Reynolds H, Karpinska B, Wingsle G, Creissen G, Mullineaux P (1999). Systemic signaling and acclimation in response to excess excitation energy in Arabidopsis. Science, 284, 654-657.

James SA, Bell DT (2000). Influence of light availability on leaf structure and growth of two Eucalyptus globulus ssp. globulus provenances. Tree Physiology, 20, 1007-1018.

Jiang CD, Wang X, Gao HY, Shi L, Chow WS (2011). Systemic regulation of leaf anatomical structure, photosynthetic performance, and high-light tolerance in sorghum. Plant Physiology, 155, 1416-1424.

Lake JA, Quick WP, Beerling DJ, Woodward FI (2001). Plant development: Signals from mature to new leaves. Nature, 
411, 154-154.

Li Q, Liu X, Yue M, Zhang XF, Zhang RC (2011). Effects of physiological integration on photosynthetic efficiency of Trifolium repens in response to heterogeneous UV-B radiation. Photosynthetica, 49, 539-545.

Long SP, Farage PK, Bolhár-Nordenkampf HR, Rohrhofer U (1989). Separating the contribution of the upper and lower mesophyll to photosynthesis in Zea mays L. leaves. Planta, 177, 207-216.

Magyar G, Kun A, Oborny B, Stuefer JF (2007). Importance of plasticity and decision-making strategies for plant resource acquisition in spatio-temporally variable environments. New Phytologist, 174, 182-193.

Murchie EH, Horton P (1997). Acclimation of photosynthesis to irradiance and spectral quality in British plant species: Chlorophyll content, photosynthetic capacity and habitat preference. Plant, Cell \& Environment, 20, 438-448.

Oguchi R, Hikosaka K, Hirose T (2003). Does the photosynthetic light-acclimation need change in leaf anatomy? Plant, Cell \& Environment, 26, 505-512.

Oguchi R, Hikosaka K, Hiura T, Hirose T (2008). Costs and benefits of photosynthetic light acclimation by tree seedlings in response to gap formation. Oecologia, 155, 665675.

Qian Y, Li D, Han L, Sun Z (2010). Inter-ramet photosynthate translocation in buffalograss under differential water deficit stress. Journal of the American Society for Horticultural Science, 135, 310-316.

Soares-Cordeiro AS, Driscoll SP, Pellny TK, Olmos E, ArrabaÇA MC, Foyer CH (2009). Variations in the dorsoventral organization of leaf structure and Kranz anatomy coordinate the control of photosynthesis and associated signalling at the whole leaf level in monocotyledonous species. Plant, Cell \& Environment, 32, 1833-1844.

Stuefer JF, During HJ, de Kroon H (1994). High benefits of clonal integration in two stoloniferous species, in response to heterogeneous light environments. Journal of Ecology, 82, 511-518.

Tao YS, Hong SC, Liao YM, Li YX, Liao XL, Quan QM (2013). Cost-benefits of the clonal integration of Cynodon dactylon, a stolon herbaceous plant, under heterogeneous lighting condition. Acta Ecologica Sinica, 33, 6509-6516. (in Chinese with English abstract) [陶应时, 洪胜春, 廖咏 梅, 黎云祥, 廖兴利, 权秋梅 (2013). 异质性光照下匍
匐茎草本狗牙根克隆整合的耗益. 生态学报, 33 , 6509-6516.]

Thomas PW, Woodward FI, Quick WP (2004). Systemic irradiance signalling in tobacco. New phytologist, 161, 193198.

van Kleunen M, Fischer M (2007). Progress in the detection of costs of phenotypic plasticity in plants. New Phytologist, 176, 727-730.

Wang N, Yu FH, Li PX, He WM, Liu FH, Liu JM, Dong M (2008). Clonal integration affects growth, photosynthetic efficiency and biomass allocation, but not the competitive ability, of the alien invasive Alternanthera philoxeroides under severe stress. Annals of Botany, 101, 671-678.

Wang XL, Li ZQ, Jiang CD, Shi L, Xing Q, Liu LA (2012). Effects of diffuse and direct light on photosynthetic function in sorghum leaf. Acta Agronomica Sinica, 38, 1452 1459. (in Chinese with English abstract) [王晓琳, 李志强, 姜闯道, 石雷, 邢全, 刘立安 (2012). 散射光和直射光 对高粱叶片光合功能的影响. 作物学报, 38, 14521459.]

Wei HJ, Yang HM, Zhao L (2007). The effects of shadowing on stomatal and photosynthetic characteristics of Trifolium repens. Pratacultural Science, 24 (10), 94-97. (in Chinese with English abstract) [韦海建, 杨惠敏, 赵亮 (2007). 遮荫环境对白三叶草气孔和光合特性的影响. 草业科 学, 24 (10), 94-97.]

Weijschedé J, Martínková J, de Kroon H, Huber H (2006). Shade avoidance in Trifolium repens: Costs and benefits of plasticity in petiole length and leaf size. New Phytologist, 172, 655-666.

Xu Z, Zhou G (2008). Responses of leaf stomatal density to water status and its relationship with photosynthesis in a grass. Journal of Experimental Botany, 59, 3317-3325.

Yu FH, Dong M (2003). Effect of light intensity and nutrient availability on clonal growth and clonal morphology of the stoloniferous herb Halerpestes ruthenica. Acta Botanica Sinica, 45, 408-416.

Yu FH, Dong M, Krüsi B (2004). Clonal integration helps Psammochloa villosa survive sand burial in an inland dune. New Phytologist, 162, 697-704.

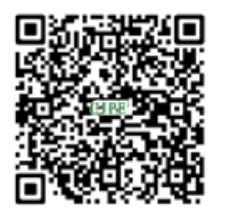

植物生态学报官网

唯一投稿网址

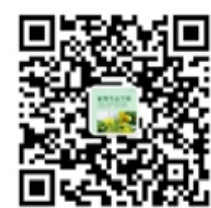

微信订阅号

期刊及学科

相关信息发布

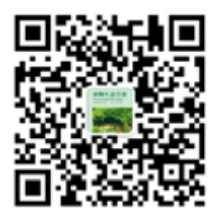

微信服务号

稿件状态查询

全文检索汶览

www.plant-ecology.com 